\title{
Spastic paraplegia gene 7 in patients with spasticity and/or optic neuropathy
}

\author{
Stephan Klebe, ${ }^{1,2,3,4, *}$ Christel Depienne, ${ }^{1,2,3,4, *}$ Sylvie Gerber, ${ }^{5, *}$ Georges Challe, $^{6}$ \\ Mathieu Anheim ${ }_{r}{ }^{4}$ Perrine Charles, ${ }^{4,7}$ Estelle Fedirko, ${ }^{4}$ Elodie Lejeune, ${ }^{4}$ Julien Cottineau, ${ }^{5}$ \\ Alfredo Brusco, ${ }^{8}$ Hélène Dollfus ${ }^{9}{ }^{\text {Patrick F. Chinnery, }}{ }^{10}$ Cecilia Mancini, $^{8}$ Xavier Ferrer, ${ }^{11}$ \\ Guilhem Sole, ${ }^{11}$ Alain Destée, ${ }^{12}$ Jean-Michel Mayer, ${ }^{7}$ Bertrand Fontaine, ${ }^{7}$ Jérôme de Seze, ${ }^{13}$ \\ Michel Clanet, ${ }^{14}$ Elisabeth Ollagnon, ${ }^{15}$ Philippe Busson, ${ }^{16}$ Cécile Cazeneuve, ${ }^{4}$ \\ Giovanni Stevanin, ${ }^{1,2,3,4,17}$ Josseline Kaplan, ${ }^{5}$ Jean-Michel Rozet, ${ }^{5}$ Alexis Brice ${ }^{1,2,3,4,7}$ and \\ Alexandra Durr ${ }^{1,2,3,4}$
}

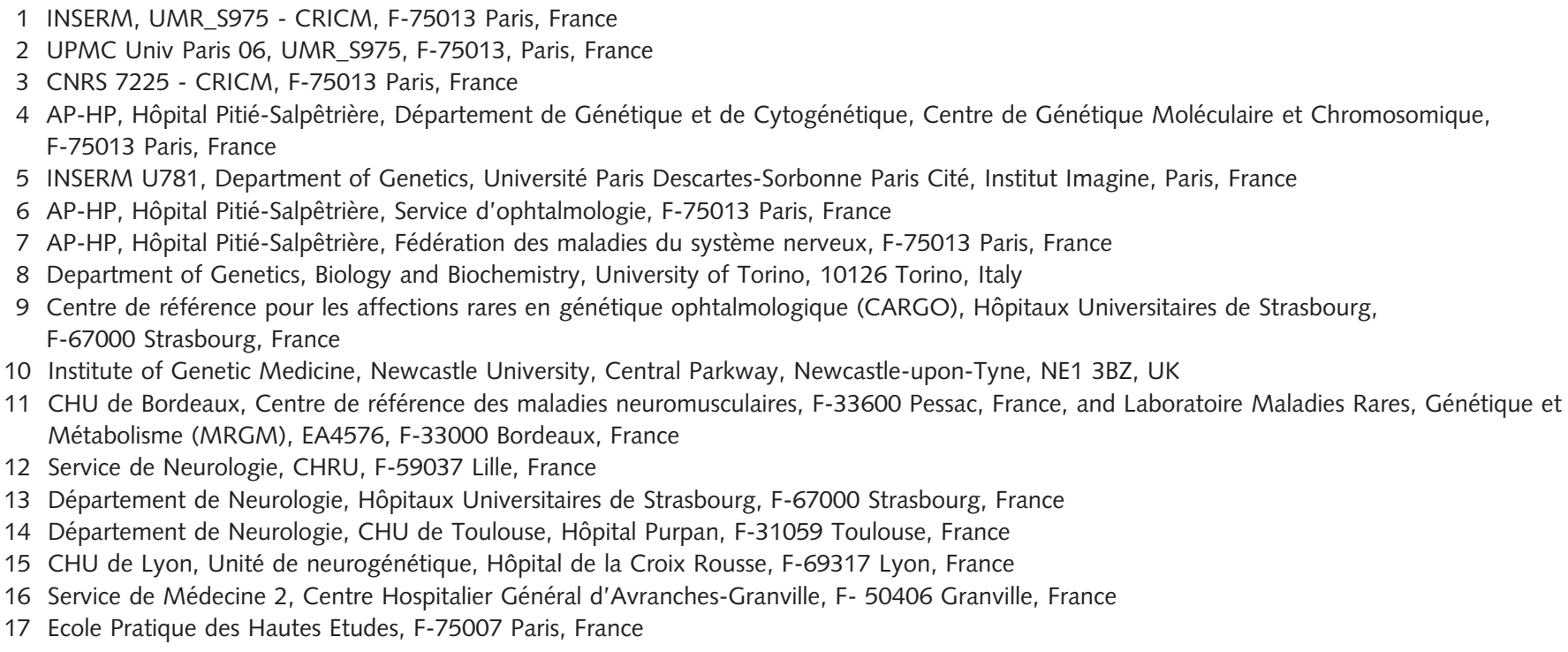

Correspondance to: Alexandra Durr, MD, PHD,

ICM Brain and Spine Institute,

CRicm UPMC, Inserm UMR_S975,

Hôpital de la Salpêtrière,

47 boulevard de l'Hôpital,

75651 Paris cedex 13,

France

E-mail: alexandra.durr@upmc.fr

*These authors contributed equally to this work.

Mutations in the spastic paraplegia 7 (SPG7) gene encoding paraplegin are responsible for autosomal recessive hereditary spasticity. We screened 135 unrelated index cases, selected in five different settings: SPG7-positive patients detected during SPG31 analysis using SPG31/SPG7 multiplex ligation-dependent probe amplification $(n=7)$; previously reported ambiguous SPG7 cases $(n=5)$; patients carefully selected on the basis of their phenotype (spasticity of the lower limbs with cerebellar 
signs and/or cerebellar atrophy on magnetic resonance imaging/computer tomography scan and/or optic neuropathy and without other signs) ( $n=24)$; patients with hereditary spastic paraparesis referred consecutively from attending neurologists and the national reference centre in a diagnostic setting $(n=98)$; and the index case of a four-generation family with autosomal dominant optic neuropathy but no spasticity linked to the SPG7 locus. We identified two SPG7 mutations in 23/134 spastic patients, $21 \%$ of the patients selected according to phenotype but only $8 \%$ of those referred directly. Our results confirm the pathogenicity of Ala510Val, which was the most frequent mutation in our series $(65 \%)$ and segregated at the homozygous state with spastic paraparesis in a large family with autosomal recessive inheritance. All SPG7-positive patients tested had optic neuropathy or abnormalities revealed by optical coherence tomography, indicating that abnormalities in optical coherence tomography could be a clinical biomarker for SPG7 testing. In addition, the presence of late-onset very slowly progressive spastic gait (median age 39 years, range 18-52 years) associated with cerebellar ataxia $(39 \%)$ or cerebellar atrophy $(47 \%)$ constitute, with abnormal optical coherence tomography, key features pointing towards SPG7-testing. Interestingly, three relatives of patients with heterozygote SPG7 mutations had cerebellar signs and atrophy, or peripheral neuropathy, but no spasticity of the lower limbs, suggesting that SPG7 mutations at the heterozygous state might predispose to late-onset neurodegenerative disorders, mimicking autosomal dominant inheritance. Finally, a novel missense SPG7 mutation at the heterozygous state (Asp411Ala) was identified as the cause of autosomal dominant optic neuropathy in a large family, indicating that some SPG7 mutations can occasionally be dominantly inherited and be an uncommon cause of isolated optic neuropathy. Altogether, these results emphasize the clinical variability associated with SPG7 mutations, ranging from optic neuropathy to spastic paraplegia, and support the view that SPG7 screening should be carried out in both conditions.

Keywords: SPG7; hereditary spastic paraparesis; optic neuropathy; cerebellar atrophy, optical coherence tomography Abbreviations: $A A A=A T P a s e s$ associated with a variety of cellular activities; MLPA = multiplex ligation-dependent probe amplification; $\mathrm{OCT}=$ optical coherence tomography

\section{Introduction}

Mutations in spastic paraplegia gene 7 (SPG7) (MIM 602783) are responsible for SPG7 hereditary spastic paraparesis, the first autosomal hereditary spastic paraplegia for which the causative gene was identified (Casari et al., 1998). However, hereditary spastic paraplegia are widely known to be clinically and genetically heterogeneous diseases with $>50$ different chromosomal loci with autosomal dominant, autosomal recessive or X-linked forms reported. In the last few years, at least 20 genes responsible for hereditary spastic paraplegia have been identified (Blackstone et al., 2011). Gene testing is consequently more and more complex, and the establishment of genotype-phenotype correlations is of great importance. In daily practice, most cases with spasticity of the lower limbs appear to be sporadic. Even when a family history is reported, the small size of the families does not always allow the mode of inheritance to be determined. Indeed, the reduced penetrance and variable expression observed in autosomal dominant forms of hereditary spastic paraplegia can mimic recessive inheritance. Although identification of the mutation in a patient has no implications for treatment as yet, it is essential for appropriate genetic counselling.

SPG7 is composed of 17 exons that contain a high frequency of rare nucleotide variants of unknown status (Elleuch et al., 2006), complicating interpretation of the results of molecular testing. Paraplegin, the protein encoded by SPG7, is a member of the AAA (ATPases associated with a variety of cellular activities) protein family (Casari et al., 1998), which is localized to the inner mitochondrial membrane (Atorino et al., 2003; Koppen et al., 2007). Paraplegin assembles with the paralogous AFG3L2 protein
(MIM 604581) to form the oligomeric mAAA protease complex involved in mitochondrial protein maturation and degradation (Leonhard et al., 2000; Nolden et al., 2005; Rugarli and Langer, 2006; Tatsuta and Langer, 2009). Interestingly, heterozygous mutations in the AFG3L2 gene are responsible for the autosomal dominant spinocerebellar ataxia SCA28, which is characterized by young adult onset, slowly progressive gait and limb ataxia, dysarthria, increased reflexes and ophthalmoparesis (Edener et al., 2010).

Mutations in SPG7 were initially reported in three families, two with isolated spasticity and one with a complex phenotype (Casari et al., 1998); however, the clinical characteristics and typical time course of the SPG7 hereditary spastic paraplegia subtype remains unclear. Cerebellar involvement and/or mild cerebellar atrophy observed on MRI scans are the most frequent additional features (Casari et al., 1998; Wilkinson et al., 2004; Elleuch et al., 2006; Warnecke et al., 2007; Brugman et al., 2008), followed by optic neuropathy (Casari et al., 1998; De Michele et al., 1998; McDermott et al., 2001), ptosis (Tzoulis et al., 2008; Warnecke et al., 2010) and supranuclear palsy (Warnecke et al., 2007). Age at onset ranges from 10 to 45 years (McDermott et al., 2001; Elleuch et al., 2006; Warnecke et al., 2007; Brugman et al., 2008; Tzoulis et al., 2008). The frequency of SPG7 mutations has varied from $1.5 \%$ to $12 \%$ among studies due to differences in inclusion criteria (Wilkinson et al., 2004; Elleuch et al., 2006; Brugman et al., 2008). The role of single heterozygous mutations in SPG7 is still unresolved at this time (McDermott et al., 2001; Elleuch et al., 2006) but a recent publication suggests a dominant effect without clinical analysis of the carriers (Sanchez-Ferrero et al., 2012). 
We present here the results of a SPG7 analysis, including sequencing and the search for micro-rearrangements in 134 patients with spastic features independently of their mode of transmission and in a four-generation family segregating autosomal dominant optic neuropathy with no spastic gait linked to the SPG7 locus. This allowed us to define the clinical and mutation spectrum of the disease associated with SPG7 and to propose guidelines as to when SPG7 should be tested in patients with hereditary spastic paraplegia and patients with autosomal dominant optic neuropathy.

\section{Materials and methods}

\section{Patients}

After obtaining informed written consent, we studied 134 unrelated hereditary spastic paraplegia index cases and 7 out of 10 affected members of a four-generation French family with isolated autosomal dominant optic neuropathy without spasticity unambiguously linked to the SPG7 locus (Figs 1 and 2). All patients with hereditary spastic paraplegia had previously tested negative in an analysis of the SPAST (SPG4) gene including direct sequencing of the coding sequence and multiplex ligation probe-dependent amplification (MLPA, kit P165). Patients with ages at onset $<10$ years were also negative for the ATL1 (SPG3A) gene. Seven patients tested SPG7-positive in a screen for SPG31 mutations including a search for rearrangements in the SPG7/SPG31 genes using the P213 MLPA kit (MRC-Holland) (Goizet et al., 2011). Five patients with autosomal recessive inheritance were previously reported by us as having only one clearly deleterious heterozygous mutation or homozygous Ala510Val mutations (Elleuch et al., 2006). One hundred and twenty-two patients were selected for de novo SPG7 screening. They were divided into two groups. One group $(n=98)$, designated as the 'routine' diagnostic group, included patients with spastic paraplegia referred consecutively by the attending neurologists. The other group $(n=24)$, designated the research group, included carefully selected patients, sampled by the clinical research network SPATAX (spastic paraplegia and cerebellar ataxia network), who consented to participate in research. The selection criteria for the research group were the presence of spastic paraparesis with cerebellar signs and/or cerebellar atrophy on MRI/CT scans and/or optic neuropathy. Patients in both groups originated mostly from France $[64 / 98(65 \%)$ and $17 / 24$ (70\%), respectively]. The remaining patients originated from North Africa $(n=18)$, Portugal $(n=7)$, Spain $(n=2)$, the Middle East $(n=2)$, Great Britain $(n=1)$, Poland $(n=1)$, Serbia $(n=1)$, Italy $(n=1)$, Columbia $(n=1)$, the West Indies $(n=2)$, Guinea $(n=1)$ and Chechnya $(n=1)$. Unfortunately, the origin of three patients was unknown. The age at onset was defined as first symptom noticed by the patient and/or relatives. The mean age at onset was $26.6 \pm 19.1$ years (range 1-65 years), and the age at examination $42.5 \pm 18.3$ years (range 2-85 years). The overall severity was moderate, but $34 \%$ of the patients needed help walking or used wheelchairs $(7 \%)$.

In the diagnostic group $(n=98)$, the patients were mostly isolated ( $n=56,57 \%) ; 32$ had an affected sib compatible with autosomal recessive transmission $(33 \%)$ and six $(6 \%)$ had a family history of dominant inheritance. No information on the family history was available for four patients (4\%). In the research group ( $n=24), 12$ patients $(50 \%)$ were isolated; six patients $(25 \%)$ had family histories compatible with autosomal recessive transmission and six $(25 \%)$ had dominant inheritance.

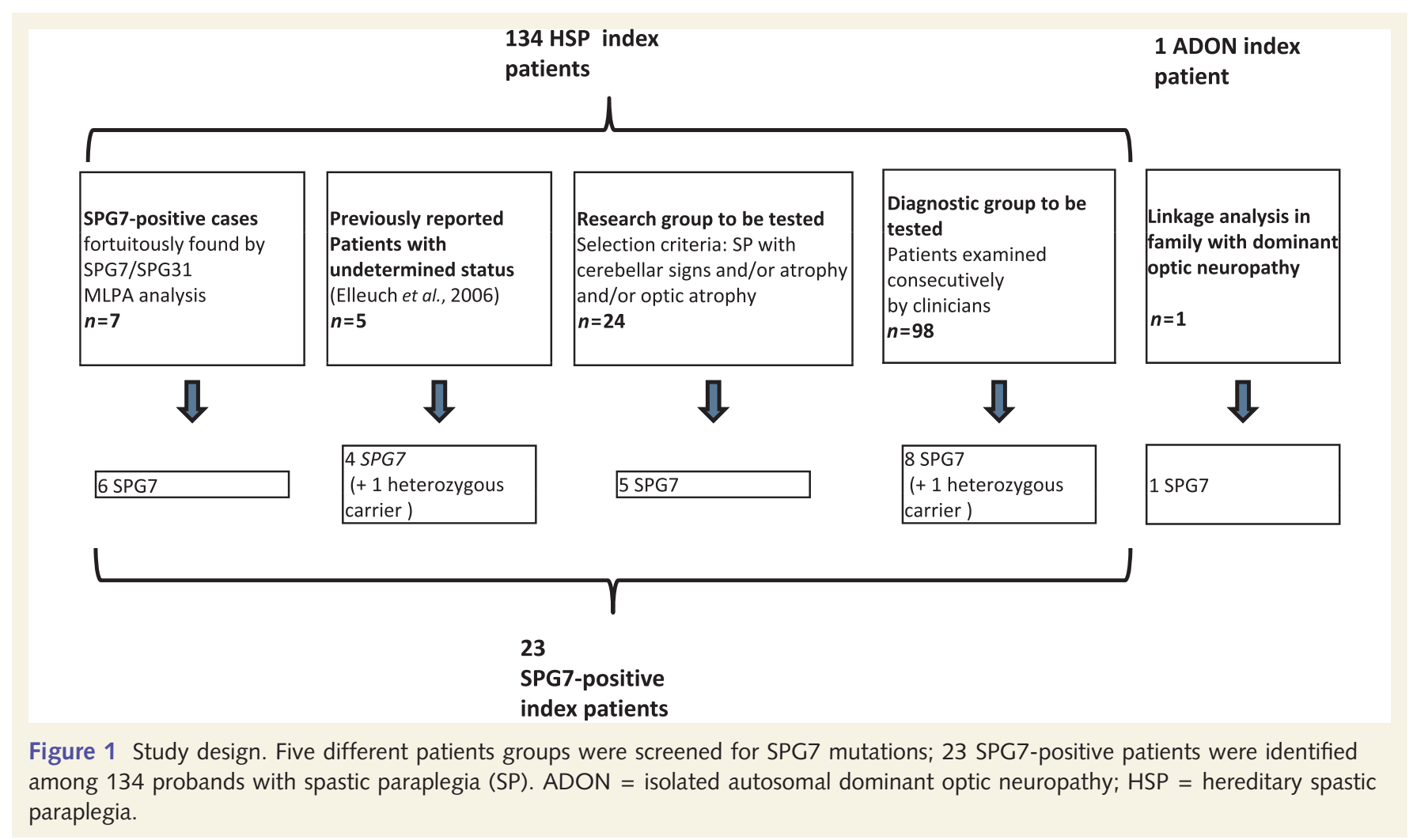




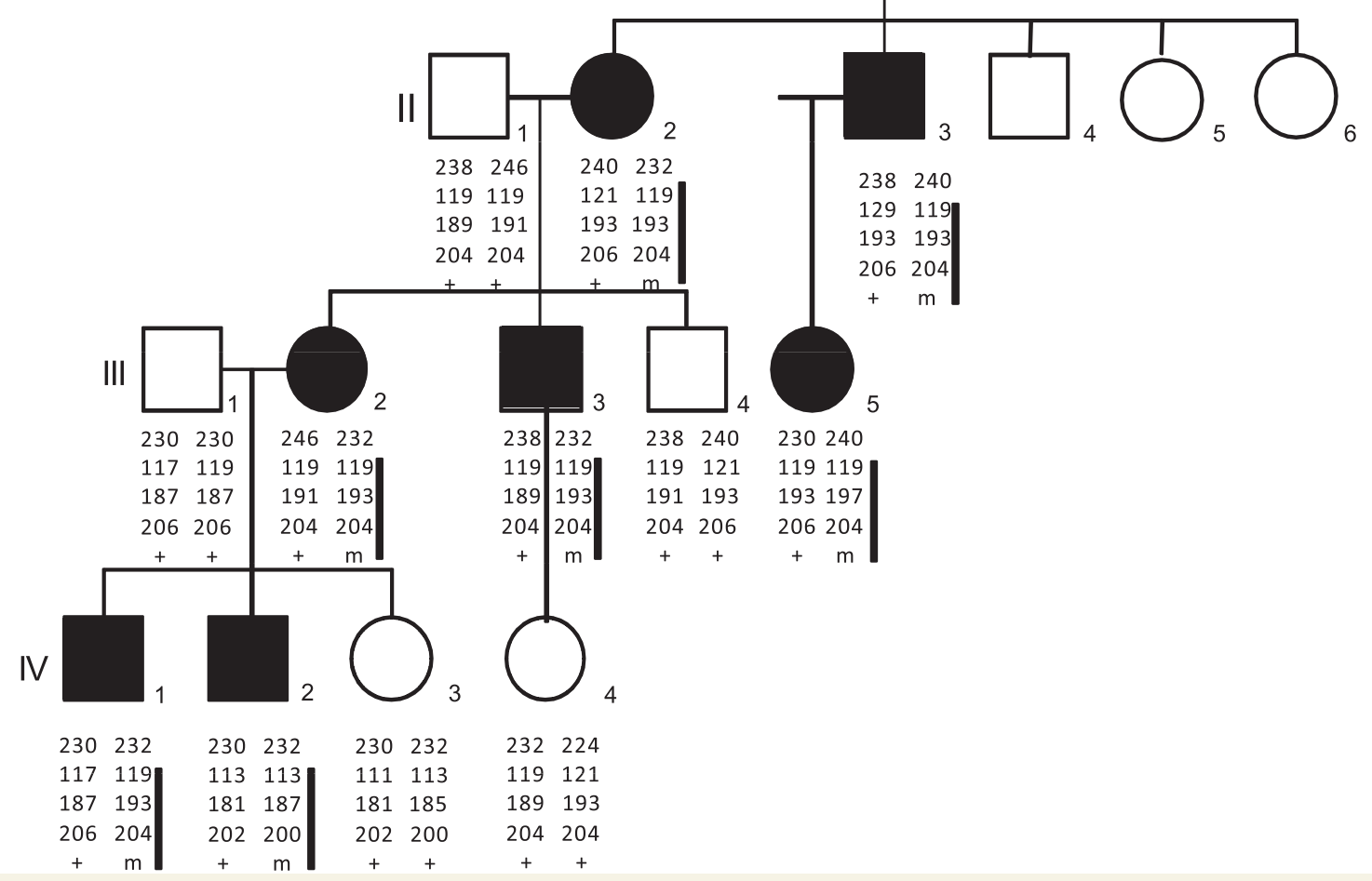

Figure 2 Pedigree of the family with autosomal dominant optic neuropathy, showing haplotypes at the SPG7 locus. Genome-wide search for linkage was performed in seven affected members using Hap300Duov2SNP Arrays (Illumina). Several candidate regions were pointed but analyses using microsatellite markers in both affected and unaffected members identified—under the hypothesis of complete penetrance-a unique candidate region on chromosome $16 q 24.3$ (maximum multipoint LOD-score $Z_{\max }=3$ ). All affected individuals segregate a common haplotype harbouring the SPG7 p.Asp411Ala mutation (black bar), absent in all unaffected individuals.

The clinical phenotype was defined as 'isolated' or 'pure' spastic paraparesis in the diagnostic group (40/98) more often than in the research group (0/24). Most patients with complicated spastic paraplegia had cerebellar signs or atrophy $(51 \%), 15 \%$ had optic neuropathy and $40 \%$ (37/92) decreased vibration sense. Additional associated symptoms included cognitive impairment $(n=14$ patients, including 12 with mental retardation and two with dementia), polyneuropathy ( $n=13$ patients, including three demyelinating sensorimotor, two axonal sensorimotor, one axonal sensitive and seven demyelinating sensitive polyneuropathy without clear information), generalized epilepsy ( $n=5)$, hearing impairment $(n=6)$, atrophy of the corpus callosum $(n=5)$, extrapyramidal symptoms $(n=3)$ and tetraspasticity $(n=1)$.

\section{Neurological examination of patients with isolated autosomal dominant optic neuropathy}

The index case (Case III3) of the four-generation family with isolated autosomal dominant optic neuropathy who has the Asp411Ala mutation in SPG7 at the heterozygous state (Family 24, Fig. 2) underwent a standardized neurological examination, conduction velocity and electromyography as well as brain MRI. In addition to the index case, none of the six affected individuals with optic neuropathy reported any gait or walking difficulties or instability.

\section{Ophthalmological examination}

Ten SPG7-positive patients with hereditary spastic paraplegia underwent a standardized ophthalmological examination of the fundus, visual field and visual acuity. It included optical coherence tomography (OCT), which provides an image of the optic disc and peripapillary region, and generates reproducible measurements of the nerve fibre layer. OCT imaging was performed with Stratus ${ }^{\circledR}$ Carl Zeiss-Meditec OCT machine, based on time-domain detection system (Carl Zeiss Meditec, Inc.).

\section{SPG7 analysis}

We amplified the whole coding region of the paraplegin gene from genomic DNA by 17 PCRs, with a primer pair for each exon, as previously described (Elleuch et al., 2006). Amplicons were directly sequenced in both directions using the Big Dye ${ }^{\circledR}$ Terminator Cycle Sequencing Ready Reaction Kit (PE Applied Biosystems). The sequence 
products were run on an $A B I 3730$ automated sequencer (PE Applied Biosystems) and the sequences analysed with SeqScape 2.5 software (PE Applied Biosystems). Mutations found in patients were searched for directly in available relatives by direct sequencing of the corresponding exon. In addition, 180 European controls (healthy spouses of patients with other neurological diseases) were included to test new variants in the SPG7 gene.

The MLPA P213 kit, designed to search for SPG7/SPG31 rearrangements, was used for all patients with hereditary spastic paraplegia (MRC-Holland). MLPA reactions were carried out according to the manufacturer's instructions. Electrophoresis of PCR products was performed using an $A B I 3730$ sequencer and MLPA data were analysed using the GeneMapper 3.5 software (Applied Biosystems). Relative ratios were calculated using the formula $r=$ mean (peak area patient/control area patient)/(peak area control individual/control area control individual).

\section{SCA28 analysis}

Exons 10, 15, 16 of $A F G 3 L 2$ (SCA28), mapping to the AAA-domain (exon 10) and M41-protease domain of the AFG3L2 protein were screened in patients with hereditary spastic paraplegia for phenotype modifiers by direct sequencing, as previously described (Cagnoli et al., 2010). All mutations so far reported in patients with SCA28 are located in one of these exons (Cagnoli et al., 2010; Di Bella et al., 2010; Edener et al., 2010).

\section{Statistical and bioinformatic analyses}

Frequency calculations and comparisons of means were performed with SPSS software. Identification of mutations and analyses of amino acid conservation in orthologues were performed with Alamut 2.0 Software (Interactive Biosoftware).

\section{Results}

\section{Genetic analyses}

\section{Patients with spasticity of the lower limbs}

While screening patients with dominant hereditary spastic paraplegia for SPG31 mutations with the P213 MLPA kit (MRC-Holland), which also contains probes for SPG7, we identified seven patients with an apparent heterozygous or homozygous deletion of one or two SPG7 exon(s). Direct sequencing of the corresponding exons and screening of the remaining SPG7 coding sequence in these patients revealed deleterious SPG7 mutations or deletions in six out of seven cases (Table 1, Patients 5-10); a synonymous polymorphism was identified in the seventh patient. In three out of the six positive patients, a pathogenic heterozygous mutation was associated with the heterozygous c.1529C > T/p.Ala510Val variant, previously described as a polymorphism and recently recognized as a hypomorphic and possibly pathogenic variant (Bonn et al., 2010).

To gain further insight into the frequency and mode of inheritance of SPG7 mutations in hereditary spastic paraplegia, we screened 122 patients divided into a routine diagnostic and a research group (see 'Materials and Methods' section) for SPG7 mutations. Five previously reported patients with undetermined status were also included (Elleuch et al., 2006). Four out of these five patients had one homozygous or two heterozygous mutations. The mutation (Met1?, Gln507X) was associated in trans with the Ala510Val mutation in two cases or with a mutation that had been missed (Leu78X) in one case (index Patient 2). In the fourth case, no other mutation or variant was found (GIn82del). In the remaining family (index Patient 3), the Ala510Val mutation perfectly segregated at the homozygous state with spastic paraplegia (Supplementary Fig. 1).

A homozygous SPG7 mutation $(n=2)$ or two heterozygous SPG7 mutations $(n=11)$ were identified in 13 of the 122 newly screened patients (10.7\%) (Table 1). Ala510Val was associated with another mutation in 9 out of 13 families. Arguments in favour of the pathogenic status of the identified changes are listed in Supplementary Table 1. In addition, none of the mutations were found in our 180 European controls. The mutations segregated perfectly with the disease in all families where this could be tested $(n=7)$ (Supplementary Fig. 1). Overall, this study reports 23 confirmed SPG7-positive patients: six were found fortuitously by MLPA analysis, four were previously considered to be of undetermined status (Elleuch et al., 2006), five patients were newly identified in the research group and eight in the diagnostic group (Fig. 1). Two patients with single heterozygous variants were still considered to have undetermined SPG7 status.

Remarkably, the proportion of patients with hereditary spastic paraplegia with mutations was comparable in families including two affected siblings $(5 / 44,11 \%)$ and in isolated cases $(7 / 71$, $10 \%)$.

The percentage of SPG7-positive patients with hereditary spastic paraplegia was higher in the selected research group $(20.8 \%$, $5 / 24)$ than in the consecutively examined diagnostic group $(8.1 \%, 8 / 98)$, although the difference was not significant $(P=0.84)$.

Compound heterozygous SPG7 mutations were found in three hereditary spastic paraplegia families with possible autosomal dominant inheritance (index Cases 6, 8 and 13). In Family 13, the mother had a heterozygous Arg485_Glu487del mutation. When examined at the age of 72 years, she had a very slight cerebellar phenotype without spasticity or pyramidal signs (Fig. 3A). The mother of Patient 5, who also had a heterozygous Arg485_Glu487del mutation, had a cerebellar gait and cerebellar atrophy on MRI (Fig. 3B). In addition, the brother of the index case in Family 3 with a heterozygous Ala510Val mutation developed a late-onset peripheral neuropathy (Supplementary Fig. 1). The patient had abolished reflexes at the age of 59 years, with pyramidal signs. Electrophysiological investigation at the age of 65 years showed that motor nerve conduction velocities and amplitudes were reduced and sensory nerve action potentials were more markedly reduced or even abolished; neurogenic changes were present. This suggested a sensory motor neuropathy of the axonal type, more marked in the lower limbs. A second examination at the age of 76 years revealed increased axonal degeneration. No common causes, such as diabetes, were found.

Overall, homozygous mutations were found in $17 \%(4 / 23)$ of the cases and compound heterozygous mutations in $83 \%(19 / 23)$. The most frequent mutation was the Ala510Val variant that was 


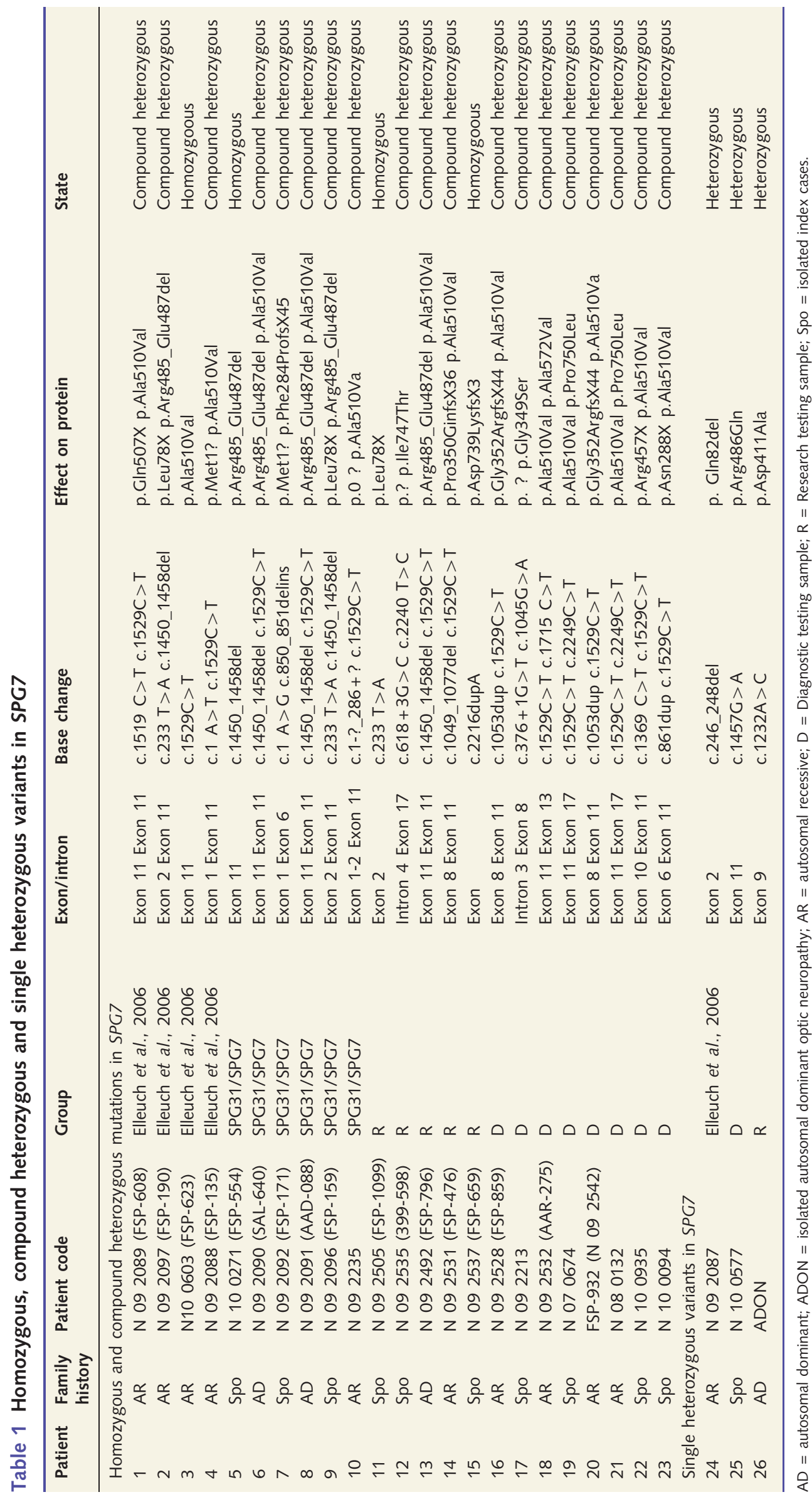




\section{A}

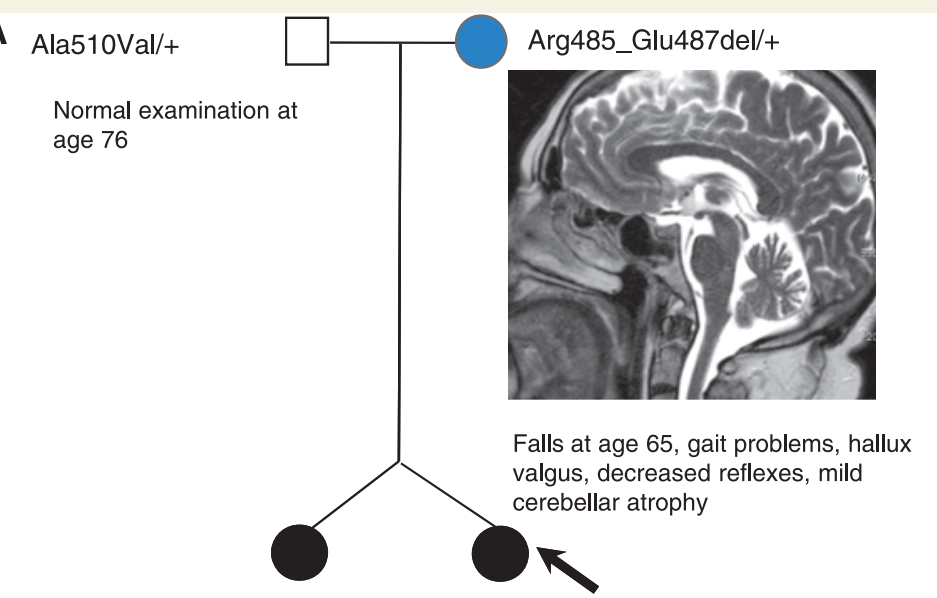

Ala510Val/Arg485_Gl u487del

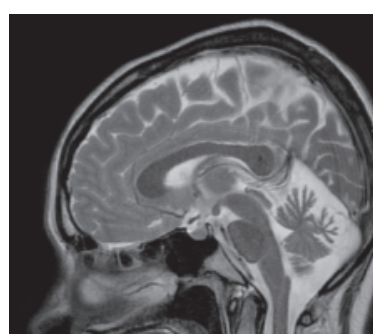

Onset at 34, cerebellar gait and pyramidal syndrome, optic atrophy

\section{Ala510Val/Arg485_Gl u487del}

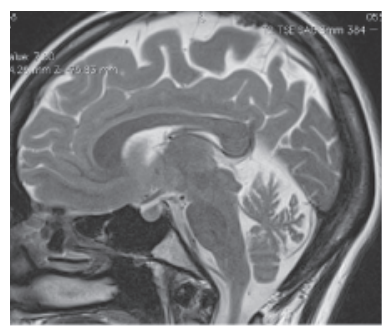

$\mathbf{N}^{\circ}$ 13: Onset at 34, cerebellar gait and pyramidal syndrome, optic atrophy
B

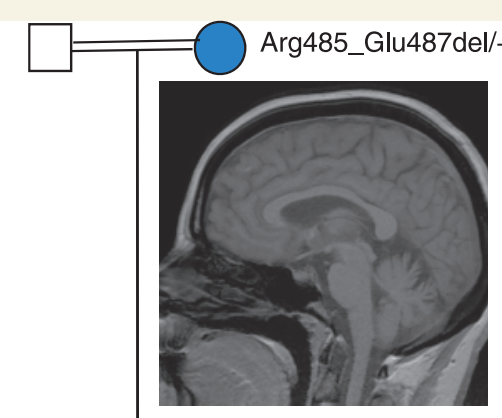

Instability at age 47 , increased reflexes with no Babinski sign, adiadochokinesia, mild cerebellar atrophy

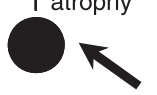

Arg485_Glu487del/Arg 485_Glu487del

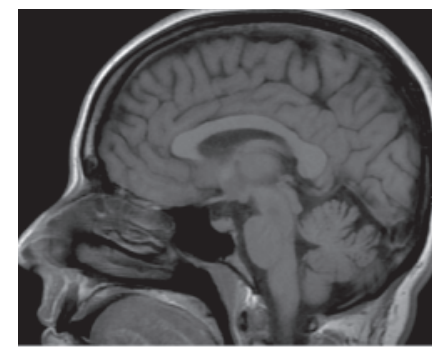

$\mathbf{N}^{\circ}$ 5: Onset at 18 , cerebellar gait and pyramidal syndrome, optic atrophy, pes cavus

Figure 3 Two SPG7 families with apparently dominant inheritance. Panels (A) and (B) show two families with SPG7 mutations and a slight cerebellar phenotype in a heterozygous parent. (A) $T_{2}$-weighted sagittal brain MRI views showing slight cerebellar atrophy in the daughters and mother. (B) $T_{1}$-weighted sagittal brain MRI showing slight vermian atrophy in the mother and the daughter.

identified in $65 \%(15 / 23)$ of the patients including one family in which the mutation was homozygous.

\section{Patients with autosomal dominant optic neuropathy}

A genome-wide linkage analysis was performed in seven affected members in a large French family with autosomal dominant optic neuropathy using Hap300Duov2SNP Arrays (Illumina). Several candidate regions were pin pointed, but analyses using microsatellite markers in both affected and unaffected members identified-under the hypothesis of complete penetrance-a unique candidate region on chromosome 16q24.3 (maximum multipoint LOD-score $Z_{\max }=3$ ). After excluding the OPA1 gene virtue of both the absence of mutations and the segregation of different haplotypes with the disease and the OPA4 (18q12, MIM605293) and OPA5 (22q12 MIM610708) loci by linkage, screening of SPG7 in the index case of the family identified a novel missense mutation c.1232A > C, p.Asp411Ala at the heterozygous state. This mutation, which affects an evolutionary conserved aspartic acid located two amino acids downstream of the Walker $B$ motif of the AAA domain of SPG7, is predicted to be deleterious by both SIFT and PolyPhen-2 prediction algorithms. It was present neither in patients with hereditary spastic paraplegia nor in 200 control individuals or databases (HapMap, 1000Genomes, Exome variant server). The analysis of other family members confirmed the perfect segregation of the mutation. All affected individuals segregate a common haplotype harbouring the SPG7 p.Asp411Ala mutation with the disease: all seven available affected members were heterozygote for the mutation whereas the two available unaffected individuals all had the normal allele (Fig. 2).

Subsequently, SPG7 was screened for mutation in an extended cohort of 152 unrelated patients affected with isolated optic neuropathies of various mode of transmission, but no additional SPG7 mutation was identified, indicating that SPG7 mutations are a rare cause of autosomal dominant optic neuropathy.

\section{Clinical features}

\section{Neurological and ophthalmological phenotype of patients with two SPG7 mutations}

Twenty-three index cases and five affected sibs had spasticity of the lower limbs. The age at onset known for 26 patients was surprisingly late, with a mean of $37.5 \pm 8.4$ years, ranging from 18 to 52 years, and a median of 39 years. Onset was significantly later in SPG7 than in non-SPG7 index cases $(36.8 \pm 8$ versus $24.8 \pm 20$, $P=0.008)$. The overall phenotype was isolated spastic gait in 14 (50\%), spasticity with overt cerebellar signs in 11 (39\%), with 
ophthalmoplegia in two and with symptomatic optic neuropathy in one patient. Interestingly, optic neuropathy was found, either by the ocular fundus examination or OCT analysis, in all SPG7-positive patients $(n=10)$ (Table 5). Only one patient (Patient 17), who used a microscope for her work, complained of problems with vision at onset of the disease. Of note, none of the SPG7-positive patients had mental retardation, polyneuropathy, epilepsy, hearing impairment, atrophy of the corpus callosum, extrapyramidal signs or tetraspasticity.

Follow-up examinations were performed in five patients after 3 (Patients 11 and 13), 7 (Patient 12), 9 (Patient 14) and 17 (Patient 3) years. Functional disability progressed slightly or moderately in all patients but one (Patient 11), but all were still able to walk without help. Optic neuropathy was detected during follow-up in two patients (Patients 11 and 14). Patient 3 developed axonal-sensorimotor polyneuropathy and subcortical dementia, 7 years after the initial examination. Results are presented in Tables 2,3 and $4(n=28)$.

\section{Ophthalmological and neurological phenotype of} patients with autosomal dominant optic neuropathy carrying the SPG7 Asp411Ala mutation

The presenting sign of all affected members $(n=8 / 10)$ was progressive and isolated visual loss in the first decade of life with a final visual acuity varying between $1 / 10$ and 3/10 in the second decade. None complained of any walking difficulties of stiffness of the legs. The identification of a SPG7 mutation segregating with the disease, prompted us to carry out a complete neurological work up of the 41-year-old index case (Patient III3, Fig. 2). He had decreased reflexes in the lower limbs without evident Babinski sign, nor spasticity at rest. His gait was unremarkable and he exhibited mild cerebellar stance and a slight tremor at the heel-shin test. Ocular gaze was limited horizontally and vertically. Conduction velocity studies showed axonal peripheral polyneuropathy and unambiguous cerebellar atrophy on MRI.

\section{Is the AFG3L2 gene (SCA28) a possible modifier of the SPG7 phenotype?}

To explain the cerebellar predominance and the presence of ophthalmoplegia, nearly constant finding in SCA28, in several SPG7positive patients, we screened exons 10, 15 and 16 of the AFG3L2 gene encoding a protein that interacts with paraplegin in search of variants that might act as modifiers. However, no variants or mutations were found in these exons.

\section{Discussion}

We report 23 index cases and five affected sibs with two SPG7 mutations from 134 families (17\%) with hereditary or sporadic spastic paraparesis identified in different settings. Homozygous or compound heterozygous SPG7 mutations were identified in $20.8 \%(5 / 24)$ of our research group patients with spasticity, but in only $8.1 \%(8 / 98)$ of the diagnostic group (Fig. 1). In all 23 cases with spastic paraparesis, an SPG7 mutation or variant was found on each copy of the gene, compatible with autosomal recessive transmission. Interestingly, the recurrent Ala510Val mutation was identified in 15 out of 23 patients with hereditary spastic paraplegia at the compound heterozygous state (in combination with another mutation) and, in one family, at the homozygous state. The pathogenicity of Ala510Val has already been suspected (McDermott et al., 2001; Wilkinson et al., 2004; Elleuch et al., 2006; Arnoldi et al., 2008; Brugman et al., 2008; Sanchez-Ferrero et al., 2012), and was confirmed by a yeast complementation assay (Bonn et al., 2010). If this variant is considered to be pathogenic, the frequency of SPG7 mutations is far greater than previously thought (at least $10 \%$ in most studies) and is comparable to the frequency determined in sporadic cases (Brugman et al., 2008).

\section{SPG7 phenotype and diagnostic criteria}

The age at onset in all SPG7 patients was late, with a median of 39 years, which confirms the finding of nearly all SPG7 studies (De Michele et al., 1998; McDermott et al., 2001; Elleuch et al., 2006; Arnoldi et al., 2008; Tzoulis et al., 2008). Interestingly, despite the fact that the age at onset was $<20$ years in $36 / 98$ (37\%) in the diagnostic and 12/24 (50\%) in the research group we did not find any patients with SPG7 in the early-onset group. All patients in our series who had onset in childhood or adolescence were negative for SPG7. Overall, the disease progressed slowly in SPG7 patients, most of whom were able to walk even after long disease durations. This was confirmed in patients who had follow-up examinations up to 17 years after the initial examination, and is consistent with previous studies (De Michele et al., 1998; Brugman et al., 2008; Tzoulis et al., 2008).

SPG7-positive patients are described as pure or complex. The major associated features in complex SPG7 patients are cerebellar signs or atrophy of the cerebellum observed by MRI imaging (Elleuch et al., 2006; Brugman et al., 2008; Tzoulis et al., 2008). In addition, bilateral optic disc pallor has been seen in several SPG7-positive families (Casari et al., 1998; De Michele et al., 1998; McDermott et al., 2001).

The traditional clinical distinction between pure and complex hereditary spastic paraplegia is difficult to maintain; however, patients might have a pure phenotype on examination, but be complex in fine, if cerebellar atrophy is detected by brain MRI or optic neuropathy by OCT.

Cerebellar involvement is not specific to SPG7 hereditary spastic paraplegia; many other hereditary spastic paraplegia subtypes present with cerebellar signs (Klebe et al., 2006; Depienne et al., 2007; Salinas et al., 2008). Interestingly, one SPG7-positive patient in this study already had cerebellar atrophy in the first 2 years of the disease (Patient 1) whereas others, without cerebellar atrophy, have only slight clinical signs 19 years after disease onset (Patient 5). Remarkably, most (5/8) of the SPG7-positive patients in the diagnostic group had neither cerebellar signs nor cerebellar atrophy (4/7). However, slight cerebellar signs can be overlooked in patients with prominent spasticity.

With respect to optic neuropathy, all patients with hereditary spastic paraplegia who underwent OCT after the SPG7 result was available had detectable pathology. Yet, only $40 \%(4 / 10)$ of this 
Table 2 Clinical features of SPG7-positive probands with spastic gait [groups Elleuch et al., (2006) and SPG31/SPG7]

\begin{tabular}{|c|c|c|c|c|c|c|c|c|c|c|}
\hline \multirow[b]{2}{*}{ Patients } & \multicolumn{4}{|c|}{ Elleuch et al., 2006} & \multicolumn{6}{|c|}{ SPG31/SPG7 } \\
\hline & 1 & 2 & 3 & 4 & 5 & 6 & 7 & 8 & 9 & 10 \\
\hline Geographic origin & France & France & France & France & France & France & France & France & France & France \\
\hline Gender & $\mathrm{F}$ & M & M & $\mathrm{F}$ & $\mathrm{F}$ & $M$ & M & $\mathrm{F}$ & $\mathrm{F}$ & $\mathrm{F}$ \\
\hline Familial history & AR & AR & AR & AR & Spo & $A D$ & Spo & $A D$ & Spo & AR \\
\hline Age at examination (follow-up) & 38 & 45 & $56(73)$ & 47 & 37 & 52 & 60 & 61 & 57 & 56 \\
\hline Age at onset & 36 & 39 & 40 & 46 & 18 & 25 & 37 & 40 & 42 & 44 \\
\hline Symptoms at onset & Stiff legs & Stiff legs & Stiff legs & US & Stiff legs & Stiff legs & Fatigue & US & US & $\begin{array}{l}\text { Stiff legs; } \\
\text { US }\end{array}$ \\
\hline Severity & Moderate & Moderate & Moderate & Moderate & Moderate & Severe & Severe & Moderate & $\begin{array}{l}\text { Unable } \\
\text { to walk }\end{array}$ & Severe \\
\hline Gait/lower limb spasticity & Mild & Moderate & Mild & Mild & Mild & Severe & Moderate & Moderate & n.a. & Moderate \\
\hline Lower limb weakness & None & Proximal LL & None & None & None & Proximal LL & None & Yes & n.a. & n.a. \\
\hline Lower limb reflexes & Increased & Increased & Normal & Increased & Increased & Increased & Increased & Increased & n.a. & Increased \\
\hline Muscle wasting & None & None & None & None & None & None & Proximal LL & Mild LL & n.a & n.a. \\
\hline Extensor plantar reflex & Yes & Yes & Yes & Yes & Yes & Yes & Yes & Yes & n.a. & Yes \\
\hline Decreased vibration at ankles & No & No & Yes & Yes & Yes & No & No & Yes & No & No \\
\hline Axial ataxia & No & No & No & Yes & No & No & No & No & No & No \\
\hline Lower limb & No & No & No & No & No & No & No & No & No & No \\
\hline Upper limb & No & No & No & No & No & No & No & No & No & No \\
\hline Nystagmus & No & & No & No & No & & & & No & \\
\hline Saccadic pursuit & No & No & No & No & No & No & No & No & Yes & No \\
\hline Dysarthria & No & No & No & No & Yes & No & No & No & No & No \\
\hline Ophthalmologic examination* & & n.a. & & & & n.a. & n.a. & n.a. & & Normal \\
\hline $\begin{array}{l}\text { Impaired oculomotricity/ } \\
\text { ophathalmoplegia }\end{array}$ & No & No & $\begin{array}{l}\text { Vertical gaze } \\
\text { limited }\end{array}$ & No & No & No & No & No & n.a. & No \\
\hline Cerebral MRI & CA & n.a. & CA (CT Scan) & Normal & Normal & n.a. & Normal & Normal & n.a. & Normal \\
\hline Optic neuropathy & Yes & n.a. & Yes & n.a. & Yes & n.a. & Yes & n.a. & n.a. & n.a. \\
\hline EMG & Normal & n.a. & n.a. & Normal & Normal & n.a. & Normal & Axonal PNP & n.a. & n.a. \\
\hline
\end{tabular}

$A D=$ autosomal dominant; $A O=A g e$ at onset $; A R=$ autosomal recessive; $C A=$ cerebellar atrophy $F=$ female; $L L=$ lower limb; $M=$ male; $n$. a. $=$ not applicable; Spo = sporadic; UL = upper limb; US = unsteadiness.

*Routine ophthalmologic examination.

subgroup had decreased visual acuity and 50\% (5/10) had optic disc pallor at the fundus (Table 5). OCT, therefore, is useful for detecting subclinical optic neuropathy, which is suggestive of an SPG7 mutation. However, OCT was performed in patients who had disease durations of at least 10 years. It would thus be interesting to determine whether optic atrophy already exists at early stages of the disease. In order to show that this is specific to SPG7 we need to screen other patients with non-SPG7 hereditary spastic paraplegia. Nevertheless, the identification of a SPG7 mutation responsible for clinically isolated optic neuropathy in a large multigenerational pedigree supports the view that the loss of retinal ganglion cells in patients with hereditary spastic paraplegia with SPG7 mutations is not coincidental. The implication of SPG7 in isolated optic neuropathies may, however, be uncommon as suggested by the absence of mutations in additional cases of hereditary optic neuropathies with various mode of inheritance and no mutation in major genes for optic neuropathy, namely mitochondrial genes responsible for Leber's hereditary optic neuropathy (LHON, OMIM 535000) and optic atrophy 1 (OPA1, OMIM 165500).

The SPG7-negative patients with complex hereditary spastic paraplegia had a large number of associated symptoms, including cognitive impairment, polyneuropathy, generalized epilepsy, hearing impairment, atrophy of the corpus callosum, extrapyramidal symptoms and tetraspasticity. Additional symptoms other than cerebellar involvement and/or optic neuropathy are exceptional in SPG7-positive patients. Warnecke and collaborators (2007) described a family with cognitive deficits including a dysexecutive syndrome and supranuclear palsy (Arnoldi et al., 2008). In our series, only one SPG7-positive patient (Patient 3) had subcortical dementia; it was observed on follow-up, at the age of 56 years, 17 years after the initial examination, and could just be coincidental.

Involvement of the cerebellum and the optic nerve in SPG7positive patients might be explained by recent pathophysiological findings concerning paraplegin, the protein encoded by SPG7. Paraplegin contains an M41 metallopeptidase domain and an ATPase domain characteristic of the AAA family of ATPases (Langer, 2000). With its paralogous AFG3L2 (OMIM 604581) subunits, it forms the oligomeric mAAA protease complex, which localizes to the inner membrane of mitochondria (Atorino et al., 2003; Koppen et al., 2007). The AFG3L2 protein has $69 \%$ and $49 \%$ sequence similarity to the yeast orthologous proteins Yta12 and Yta10, respectively (Banfi et al., 1999). The mAAA protease mediates protein degradation and activation in mitochondria (Leonhard et al., 2000; Rugarli and Langer, 2006; Tatsuta and Langer, 2009). Very recently, heterozygous missense mutations in the AFG3L2 gene were found to cause spinocerebellar ataxia type 28 (SCA28; OMIM 610246) (Di Bella et al., 2010). The associated clinical characteristics of heterozygous SCA28 patients include pyramidal signs, ptosis and ophthalmoplegia (Cagnoli et al., 2010; Di Bella et al., 2010). Patients with homozygous 
Table 3 Clinical features of SPG7-positive probands with spastic gait (Research group)

\begin{tabular}{|c|c|c|c|c|c|}
\hline Patient & 11 & 12 & 13 & 14 & 15 \\
\hline Geographic origin & France & Maroc & France & France & France \\
\hline Gender & $\mathrm{F}$ & M & $\mathrm{F}$ & $\mathrm{F}$ & M \\
\hline Familial history & Spo & Spo & $A D$ & $A R$ & Spo \\
\hline Age at examination (follow up) & $54(57)$ & $42(49)$ & $42(45)$ & $43(52)$ & 45 \\
\hline Age at onset & 44 & 32 & 34 & 37 & 40 \\
\hline Symptoms at onset & US & US & visual blurring & Stiff legs & Stiff legs \\
\hline Severity & Severe & Severe & Moderate & Moderate & Mild \\
\hline Gait/LL spasticity & Moderate & Moderate & Mild & Moderate & Mild \\
\hline LL weakness & None & None & None & n.a. & None \\
\hline LL reflexes & Increased & Increased & Increased & Increased & Increased \\
\hline Muscle wasting & None & Distal LL & None & n.a. & None \\
\hline Extensor plantar reflex & Yes & Yes & Yes & n.a. & Yes \\
\hline Decreased vibration at ankles & Yes & Normal & Yes & Normal & Yes \\
\hline Axial ataxia & No & No & Yes & Yes & No \\
\hline Lower $\operatorname{limb}$ & No & No & No & No & No \\
\hline Upper limb & No & Yes & No & No & No \\
\hline Nystagmus & No & No & No & Yes & No \\
\hline Saccadic pursuit & No & No & Yes & Yes & Yes \\
\hline Dysarthria & No & No & Yes & No & Yes \\
\hline \multicolumn{6}{|l|}{ Ophthalmologic examination* } \\
\hline $\begin{array}{l}\text { Impaired oculomotricity/ } \\
\text { ophathalmoplegia }\end{array}$ & No & Vertical gaze limited & No & No & No \\
\hline Cerebral MRI & CA & CA, global atrophy pons & CA & Normal & $\begin{array}{l}\text { Upper vermis } \\
\text { atrophy }\end{array}$ \\
\hline Optic neuropathy & Yes & n.a. & Yes & Yes & Yes \\
\hline EMG & n.a. & n.a. & n.a. & n.a. & n.a. \\
\hline
\end{tabular}

$\mathrm{AD}=$ autosomal dominant; $\mathrm{AR}=$ autosomal recessive; $\mathrm{CA}=$ cerebellar atrophy; $\mathrm{F}=$ female; $\mathrm{LL}=$ lower limb; $M=\mathrm{male} ; \mathrm{n} . \mathrm{a} .=\mathrm{not}$ applicable; Spo = sporadic; $\mathrm{UL}=$ upper limb; US = unsteadiness.

${ }^{*}$ Routine ophthalmologic examination.

AFG3L2 mutations have a more severe phenotype that includes oculomotor apraxia, dystonia and progressive myoclonic epilepsy (Pierson et al., 2011). This suggests that some of the clinical heterogeneity and the variable severity of cerebellar involvement in SPG7 might be due to variants in AFG3L2 that act as genetic modifiers. Therefore, in SPG7-positive patients we analysed exons 10, 15 and 16 of $A F G 3 L 2$, in which all of the reported mutations are located (Cagnoli et al., 2010; Di Bella et al., 2010; Pierson et al., 2011). No variants were found, although variants in other exons or non-coding regions of the gene might have been missed.

The underlying pathophysiology in SPG7 and the multisystem involvement observed in some SPG7-positive patients are typical of mitochondrial disorders, particularly the presence of optic neuropathy. The loss of retinal ganglion cells is indeed a hallmark of mitochondrial disorders including neurodegenerative diseases due to mitochondrial defects like Friedreich ataxia or Charcot-MarieTooth type 2A2 (Fortuna et al., 2009; Rouzier et al., 2012). The optic neuropathy may even be the unique symptom of mitochondrial dysfunction as in Leber's hereditary optic neuropathy (OMIM 535000), OPA1 (OMIM 165500) or OPA7 (Hanein et al., 2009). The sensitivity of retinal ganglion cells to mitochondrial dysfunction is thought to result from a particularly high energy dependence and vulnerability (Marelli et al., 2011; Yu-Wai-Man et al., 2011a). Interestingly, the mAAA proteases have been reported to play a role in the processing of the OPA1 protein (Martinelli and Rugarli, 2010). Therefore, it is possible that mutations in SPG7 cause loss of retinal ganglion cells through alteration of the OPA1 function. With respect to the Asp411Ala mutation segregating with isolated autosomal dominant optic neuropathy with neuropathy but no hereditary spastic paraplegia, it is important to note that it is located in the AAA domain of the protein, two amino acids downstream of the Walker B motif (residues 405409). This motif is involved with the upstream Walker A motif in the fixation and hydrolysis of ATP. To our knowledge this is the only naturally occurring missense mutation identified in this region of the protein. Interestingly, a human SPG7 protein harbouring the $\mathrm{p.E408Q}$ mutation in the Walker B motif has been expressed in addition to wild-type AFG3L2 in a Saccharomyces cerevisiae strain lacking both YAT11 and YTA12. This mutation had a dominant negative effect on both the AFG3L2 homohexamers and the paraplegin/AFG3L2 heterohexamer with reduced ATPase and proteolytic activities (Augustin et al., 2009). It is likely that the Asp411Ala mutation interferes with the binding and/or hydrolysis of ATP by the neighbouring Walker B domain leading to decreased proteolytic activity of mAAA proteases in retinal ganglion cells. The retinal-restricted expression of the disease in patients harbouring the mutation is consistent with exacerbated vulnerability of retinal ganglion cells (Marelli et al., 2011; Yu-Wai-Man et al., 2011b). 
Table 4 Clinical features of SPG7-positive probands with spastic gait (Diagnostic group)

\begin{tabular}{|c|c|c|c|c|c|c|c|c|}
\hline Patient & 16 & 17 & 18 & 19 & 20 & 21 & 22 & 23 \\
\hline Geographic origin & France & France & France & France & UK & France & France & France \\
\hline Gender & $M$ & $\mathrm{~F}$ & $\mathrm{~F}$ & $M$ & $\mathrm{~F}$ & $\mathrm{~F}$ & $M$ & $\mathrm{~F}$ \\
\hline Familial history & $A R$ & Spo & AR & Spo & AR & AR & Spo & Spo \\
\hline Age at examination & 71 & 55 & 57 & 55 & 43 & 37 & 36 & 57 \\
\hline Age at onset & n.a. & 52 & 45 & 20 & 30 & 30 & 31 & 43 \\
\hline Symptoms at onset & n.a. & Stiff legs; US & US & n.a. & Stiff legs & Stiff legs & Stiff legs; cramps & Stiff legs; US \\
\hline Severity & n.a. & Moderate & Mild & Moderate & n.a. & Moderate & Severe & Moderate \\
\hline Gait/LL spasticity & n.a. & Moderate & None & n.a. & n.a. & Moderate & Moderate & Moderate \\
\hline LL weakness & n.a. & Proximal LL & None & None & n.a. & Proximal/distal LL & Proximal/distal LL & Proximal/distal LL \\
\hline LL reflexes & n.a. & Increased & Increased & n.a. & n.a. & Increased & Increased & Increased \\
\hline Muscle wasting & n.a. & None & None & None & n.a. & None & None & None \\
\hline Extensor plantar reflex & n.a. & Yes & No & Yes & n.a. & Yes & Yes & Yes \\
\hline Decreased vibration at ankles & Yes & No & Normal & n.a. & n.a. & Yes & No & Yes \\
\hline Axial ataxia & n.a. & No & Yes & No & No & Yes & No & No \\
\hline Lower limb & n.a. & No & No & No & No & Yes & No & No \\
\hline Upper limb & n.a. & No & No & No & No & No & No & No \\
\hline Nystagmus & & & No & & & No & & \\
\hline Saccadic pursuit & n.a. & No & No & No & No & No & No & No \\
\hline Dysarthria & n.a. & No & No & Yes & No & Yes & No & No \\
\hline Ophthalmologic examination* & n.a. & Normal & & n.a. & Normal & Normal & Normal & Optic atrophy \\
\hline $\begin{array}{l}\text { Impaired oculomotricity/ } \\
\text { ophathalmoplegia }\end{array}$ & n.a. & No & No & n.a. & No & No & No & No \\
\hline Cerebral MRI & n.a. & Normal & $C A$ & CA & Normal & $C A$ & Normal & Normal \\
\hline Optic neuropathy & n.a. & n.a. & Yes & n.a. & n.a. & n.a. & n.a. & n.a. \\
\hline EMG & n.a. & Normal & n.a. & n.a. & n.a. & Normal & n.a. & n.a. \\
\hline
\end{tabular}

$\mathrm{AD}=$ autosomal dominant; $\mathrm{AR}=$ autosomal recessive; $\mathrm{CA}=$ cerebellar atrophy; $\mathrm{F}=$ female; $\mathrm{LL}=$ lower limb; $M=$ male; $\mathrm{n} . \mathrm{a} .=$ not applicable; Spo $=$ sporadic; $\mathrm{UL}$ upper limb; US = unsteadiness.

${ }^{*}$ Routine ophthalmologic examination.

Table 5 Ophthalmological findings in 10 SPG7-positive patients with spastic gait

\begin{tabular}{|c|c|c|c|c|c|c|c|}
\hline Patient & $\begin{array}{l}\text { Age at } \\
\text { examination } \\
\text { (disease duration) }\end{array}$ & $\begin{array}{l}\text { Papillary aspect } \\
\text { on funduscopy }\end{array}$ & $\begin{array}{l}\text { OCT (normal } \\
>110 \mu \mathrm{m}, \\
\text { Left-Right) }\end{array}$ & Eye movements & $\begin{array}{l}\text { Visual } \\
\text { field }\end{array}$ & $\begin{array}{l}\text { Visual } \\
\text { acuity/10 }\end{array}$ & Conclusion \\
\hline 1 & $58(22)$ & normal & $106-103$ & $\begin{array}{l}\text { limited gaze horizontal } \\
\text { bilateral }\end{array}$ & ND & 10 & Optic sectorial atrophy \\
\hline 3 & $74(34)$ & mild pallor & $83-83$ & $\begin{array}{l}\text { slow saccades, vertical } \\
\text { limited gaze }\end{array}$ & normal & 7 & Optic neuropathy \\
\hline 5 & 37 (19) & mild pallor & $79-80$ & normal & ND & 10 & Optic neuropathy \\
\hline 7 & $60(23)$ & normal & 97 sectorial & normal & ND & 10 & Optic neuropathy \\
\hline 11 & $56(12)$ & mild pallor & $70-76$ & $\begin{array}{l}\text { limited gaze horizontal } \\
\text { bilateral }\end{array}$ & normal & 10 & Optic neuropathy \\
\hline 13 & $44(10)$ & mild pallor & $93-94$ & ND & & 10 & Optic neuropathy \\
\hline 14 & $52(15)$ & normal & 103-102 & normal & ND & 8 & Optic neuropathy \\
\hline 15 & $52(12)$ & normal & 94-109 & slow saccades, hypometric & ND & 10 & Optic neuropathy \\
\hline 18 & $66(21)$ & mild pallor & $95-100$ & normal & normal & $\begin{array}{l}8 \text { Left } 9 \\
\text { Right }\end{array}$ & Optic neuropathy \\
\hline 23 & 59 (16) & mild pallor & 93 sectorial & normal & abnormal & 6 & Optic neuropathy \\
\hline
\end{tabular}

$\mathrm{ND}=$ not determined

\section{Do heterozygous mutations predispose to a cerebellar syndrome or atrophy?}

Two patients in this study had only one heterozygous variant (Glu82del and Arg486Gln). Arg486Gln is a rare variant (rs111475461) that was found in healthy individuals at a low frequency (minor allele frequency of 0.002 in dbSNP) (McDermott et al., 2001), suggesting that it is not pathogenic. Although Glu82del was not found in controls (Elleuch et al., 2006), the patient with this variant had nystagmus, hearing impairment and 


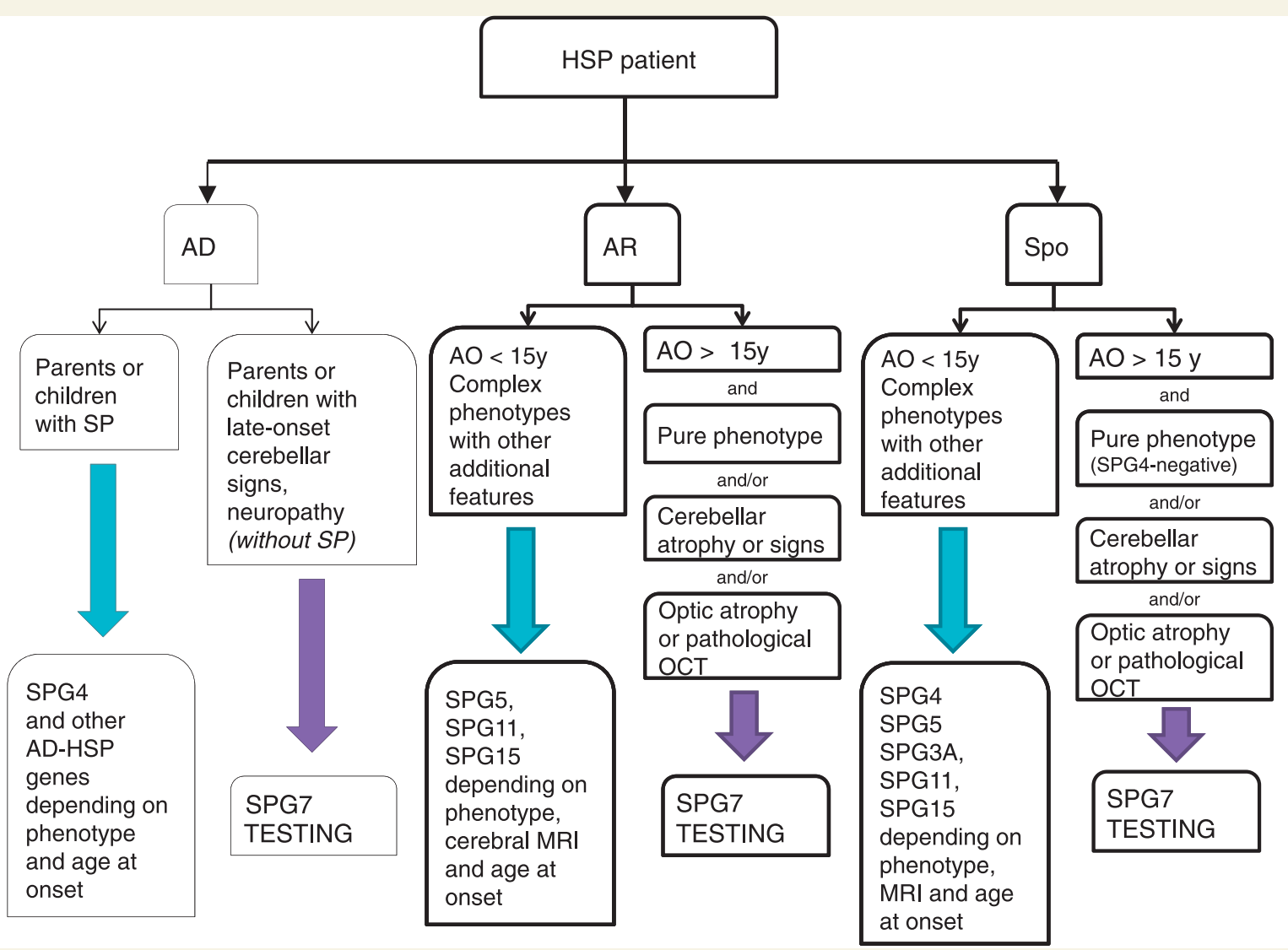

Figure 4 Flow chart to guide testing for SPG7 in patients with spastic paraparesis. AD = autosomal dominant; $A O=$ age at onset; $\mathrm{AR}=$ autosomal recessive; HSP = hereditary spastic paraplegia; $\mathrm{SP}=$ spastic paraplegia; $\mathrm{Spo}=$ sporadic; $\mathrm{y}=$ years.

mental retardation in addition to spastic paraplegia, suggesting that a gene other than SPG7 could be responsible for this complex phenotype.

Nevertheless, at least three index cases with SPG7 mutations had a family history compatible with autosomal dominant transmission (Patients 6, 8 and 13; Table 1 and Fig. 3). The mother of index Case 13, who carried a heterozygous Arg485_Glu487del mutation, had a slight cerebellar phenotype on examination (Fig. 3A). The mother of Patient 5, who also carried a heterozygous Arg485_Glu487del mutation, had cerebellar gait and cerebellar atrophy on MRI (Fig. 2B). Finally, one individual in Family 3 with a heterozygous Ala510Val mutation developed an axonal sensory motor neuropathy with pyramidal signs. A patient with a compound heterozygous Arg485_487del and Ala510Val mutations was previously reported to have an affected father with a heterozygous Arg485_487del mutation (McDermott et al., 2001). The authors concluded that the Ala510Val mutation might act as genetic modifier, whereas the Arg485_487del mutation is a disease causing dominant allele (McDermott et al., 2001). These observations suggest that a single SPG7 mutation may constitute a susceptibility factor for a late-onset neurodegenerative disorder the nature of which would depend on the identity of the mutation. Interestingly, diffusion tensor imaging recently confirmed subclinical abnormalities in heterozygous SPG7 mutation carriers (Warnecke et al., 2010). It should be noted, in any case, that cerebellar ataxia always developed later in carriers of a single heterozygous mutation than in their relatives with SPG7 hereditary spastic paraplegia; their ataxia was also less severe.

\section{Conclusion and decision-making}

Our study has shown that SPG7 mutations are a frequent cause of middle-aged onset of spastic gait when strict inclusion criteria are applied. SPG7 should, therefore, be tested in autosomal recessive or sporadic hereditary spastic paraplegia, particularly if it is associated with cerebellar atrophy/cerebellar signs and/or optic neuropathy, or if OCT reveals the presence of pathology even in the absence of decreased visual acuity (Fig. 4). Our data also demonstrate that SPG7 mutations are unlikely to be found in young-onset hereditary spastic paraplegia and in patients with a complicated phenotype that differs from the proposed inclusion criteria. Finally, although uncommon, we show here that SPG7 mutations may account for isolated optic neuropathy with peripheral neuropathy. This suggests that systematic neurological examinations in individuals with clinically isolated optic atrophy could help in identifying SPG7-positive patients. 


\section{Acknowledgements}

The authors thank the families for their participation, the DNA and cell bank for DNA extraction and cell culture and the clinicians, more particularly Vincent Meininger, Olivier Lyon-Caen, Nadine Leforestier, Anne-Marie Ouvrard, Jean-Claude Labouret, Christophe Vial, for referring their patients to the diagnostic unit for analysis of genes involved in spastic paraplegia.

\section{Funding}

This work was supported by AP-HP and INS. PFC is an Honorary Consultant Neurologist at Newcastle upon Tyne Foundation Hospitals NHS Trust, a Wellcome Trust Senior Fellow in Clinical Science (084980/Z/08/Z) and a UK NIHR Senior Investigator. PFC receives additional support from the Wellcome Trust Centre for Mitochondrial Research (096919Z/11/Z), the Medical Research Council (UK) Centre for Translational Muscle Disease research, the Association Française contre les Myopathies, EU FP7 TIRCON, the Association Retina France and the UK NIHR Biomedical Research Centre for Ageing and Age-related disease award to the Newcastle upon Tyne Foundation Hospitals NHS Trust.

\section{Supplementary material}

Supplementary material is available at Brain online.

\section{References}

Arnoldi A, Tonelli A, Crippa F, Villani G, Pacelli $C$, Sironi $M$, et al. A clinical, genetic, and biochemical characterization of SPG7 mutations in a large cohort of patients with hereditary spastic paraplegia. Hum Mutat 2008; 29: 522-31.

Atorino L, Silvestri L, Koppen M, Cassina L, Ballabio A, Marconi R, et al. Loss of m-AAA protease in mitochondria causes complex I deficiency and increased sensitivity to oxidative stress in hereditary spastic paraplegia. J Cell Biol 2003; 163: 777-87.

Augustin S, Gerdes F, Lee S, Tsai FT, Langer T, Tatsuta T. An intersubunit signaling network coordinates ATP hydrolysis by m-AAA proteases. Mol Cell 2009; 35: 574-85.

Banfi S, Bassi MT, Andolfi G, Marchitiello A, Zanotta S, Ballabio A, et al. Identification and characterization of AFG3L2, a novel parapleginrelated gene. Genomics 1999; 59: 51-8.

Blackstone C, O'Kane CJ, Reid E. Hereditary spastic paraplegias: membrane traffic and the motor pathway. Nat Rev Neurosci 2011; 12: 31-42.

Bonn F, Pantakani K, Shoukier M, Langer T, Mannan AU. Functional evaluation of paraplegin mutations by a yeast complementation assay. Hum Mutat 2010; 31: 617-21.

Brugman F, Scheffer $\mathrm{H}$, Wokke JH, Nillesen WM, de Visser M, Aronica E, et al. Paraplegin mutations in sporadic adult-onset upper motor neuron syndromes. Neurology 2008; 71: 1500-5.

Cagnoli C, Stevanin G, Brussino A, Barberis M, Mancini C, Margolis RL, et al. Missense mutations in the AFG3L2 proteolytic domain account for approximately $1.5 \%$ of European autosomal dominant cerebellar ataxias. Hum Mutat 2010; 31: 1117-24.

Casari G, De Fusco M, Ciarmatori S, Zeviani M, Mora M, Fernandez P, et al. Spastic paraplegia and OXPHOS impairment caused by mutations in paraplegin, a nuclear-encoded mitochondrial metalloprotease. Cell 1998; 93: 973-83.

De Michele G, De Fusco M, Cavalcanti F, Filla A, Marconi R, Volpe G, et al. A new locus for autosomal recessive hereditary spastic paraplegia maps to chromosome 16q24.3. Am J Hum Genet 1998; 63: 135-9.

Depienne C, Stevanin G, Brice A, Durr A. Hereditary spastic paraplegias: an update. Curr Opin Neurol 2007; 20: 674-80.

Di Bella D, Lazzaro F, Brusco A, Plumari M, Battaglia G, Pastore A, et al. Mutations in the mitochondrial protease gene AFG3L2 cause dominant hereditary ataxia SCA28. Nat Genet 2010; 42: 313-21.

Edener U, Wollner J, Hehr U, Kohl Z, Schilling S, Kreuz F, et al. Early onset and slow progression of SCA28, a rare dominant ataxia in a large four-generation family with a novel AFG3L2 mutation. Eur J Hum Genet 2010; 18: 965-8.

Elleuch N, Depienne C, Benomar A, Hernandez AM, Ferrer X, Fontaine B, et al. Mutation analysis of the paraplegin gene (SPG7) in patients with hereditary spastic paraplegia. Neurology 2006; 66: 654-9.

Fortuna F, Barboni P, Liguori R, Valentino ML, Savini G, Gellera C, et al. Visual system involvement in patients with Friedreich's ataxia. Brain 2009; 132 (Pt 1): 116-23.

Goizet C, Depienne C, Benard G, Boukhris A, Mundwiller E, Sole G, et al. REEP1 mutations in SPG31: frequency, mutational spectrum, and potential association with mitochondrial morpho-functional dysfunction. Hum Mutat 2011; 32: 1118-27.

Hanein S, Perrault I, Roche O, Gerber S, Khadom N, Rio $M$, et al. TMEM126A, encoding a mitochondrial protein, is mutated in autosomal-recessive nonsyndromic optic atrophy. Ame J Hum Genet 2009; 84: 493-8.

Klebe S, Azzedine H, Durr A, Bastien P, Bouslam N, Elleuch N, et al. Autosomal recessive spastic paraplegia (SPG30) with mild ataxia and sensory neuropathy maps to chromosome 2q37.3. Brain 2006; 129 (Pt 6): 1456-62.

Koppen M, Metodiev MD, Casari G, Rugarli El, Langer T. Variable and tissue-specific subunit composition of mitochondrial m-AAA protease complexes linked to hereditary spastic paraplegia. Mol Cell Biol 2007; 27: 758-67.

Langer T. AAA proteases: cellular machines for degrading membrane proteins. Trends Biochem Sci 2000; 25: 247-51.

Leonhard K, Guiard B, Pellecchia G, Tzagoloff A, Neupert W, Langer T. Membrane protein degradation by AAA proteases in mitochondria: extraction of substrates from either membrane surface. Mol Cell 2000; 5: 629-38.

Marelli C, Amati-Bonneau P, Reynier P, Layet V, Layet A, Stevanin G, et al. Heterozygous OPA1 mutations in Behr syndrome. Brain 2011; 134 (Pt 4): e169; author reply e70.

Martinelli P, Rugarli El. Emerging roles of mitochondrial proteases in neurodegeneration. Biochim Biophys Acta 2010; 1797: 1-10.

McDermott CJ, Dayaratne RK, Tomkins J, Lusher ME, Lindsey JC, Johnson MA, et al. Paraplegin gene analysis in hereditary spastic paraparesis (HSP) pedigrees in northeast England. Neurology 2001; 56: 467-71.

Nolden $M$, Ehses S, Koppen M, Bernacchia A, Rugarli El, Langer T. The $\mathrm{m}$-AAA protease defective in hereditary spastic paraplegia controls ribosome assembly in mitochondria. Cell 2005; 123: 277-89.

Pierson TM, Adams D, Bonn F, Martinelli P, Cherukuri PF, Teer JK, et al. Whole-exome sequencing identifies homozygous AFG3L2 mutations in a spastic ataxia-neuropathy syndrome linked to mitochondrial m-AAA proteases. PLoS Genet 2011; 7: e1002325.

Rouzier C, Bannwarth S, Chaussenot A, Chevrollier A, Verschueren A, Bonello-Palot N, et al. The MFN2 gene is responsible for mitochondrial DNA instability and optic atrophy 'plus' phenotype. Brain 2012; 135 (Pt 1): 23-34.

Rugarli El, Langer T. Translating m-AAA protease function in mitochondria to hereditary spastic paraplegia. Trends Mol Med 2006; 12: 262-9.

Salinas S, Proukakis C, Crosby A, Warner TT. Hereditary spastic paraplegia: clinical features and pathogenetic mechanisms. Lancet Neurol 2008; 7: 1127-38. 
Sanchez-Ferrero E, Coto E, Beetz C, Gamez J, Corao A, Diaz M, et al. SPG7 mutational screening in spastic paraplegia patients supports a dominant effect for some mutations and a pathogenic role for p.A510V. Clin Genet 2012. Advance Access published on May 10, 2012, doi:10.1111/j.1399-0004.2012.01896.x.

Tatsuta T, Langer T. AAA proteases in mitochondria: diverse functions of membrane-bound proteolytic machines. Res Microbiol 2009; 160: 711-7.

Tzoulis C, Denora PS, Santorelli FM, Bindoff LA. Hereditary spastic paraplegia caused by the novel mutation 1047insC in the SPG7 gene. $J$ Neurol 2008; 255: 1142-4.

Warnecke T, Duning T, Schirmacher A, Mohammadi S, Schwindt W, Lohmann $\mathrm{H}$, et al. A novel splice site mutation in the SPG7 gene causing widespread fiber damage in homozygous and heterozygous subjects. Mov Disord 2010; 25: 413-20.
Warnecke T, Duning T, Schwan A, Lohmann H, Epplen JT, Young P. A novel form of autosomal recessive hereditary spastic paraplegia caused by a new SPG7 mutation. Neurology 2007; 69: 368-75.

Wilkinson PA, Crosby AH, Turner C, Bradley LJ, Ginsberg L, Wood NW, et al. A clinical, genetic and biochemical study of SPG7 mutations in hereditary spastic paraplegia. Brain 2004; 127 (Pt 5): 973-80.

Yu-Wai-Man P, Bailie M, Atawan A, Chinnery PF, Griffiths PG. Pattern of retinal ganglion cell loss in dominant optic atrophy due to OPA1 mutations. Eye (Lond) 2011a; 25: 596-602.

Yu-Wai-Man P, Griffiths PG, Chinnery PF. Mitochondrial optic neuropathies - disease mechanisms and therapeutic strategies. Prog Retin Eye Res 2011b; 30: 81-114. 